\title{
Quantile regression, VaR and CVAR. An empirical beta comparison of the techniques in relation to credit risk.
}

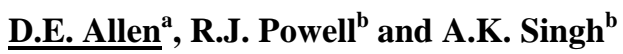 \\ ${ }^{a}$ Centre for Applied Financial Studies, University of South Australia and School of Mathematics and \\ Statistics, University of Sydney, Australia. \\ ${ }^{b}$ School of Business, Edith Cowan University, Australia \\ Email: r.powell@ecu.edu.au
}

\begin{abstract}
This study focuses on the credit risk of Australian financial institutions relative to that of the US. These two countries are chosen because the study is undertaken in Australia, and because Australia is widely considered to have fared far better than the US during the Global Financial (GFC) in terms of both share market volatility and credit defaults, our comparison involves two countries experiencing very different circumstances. The key questions addressed by the paper are firstly, the extent to which the credit risk of Australian financial institutions compares favourably (or otherwise) to the US, and secondly whether credit risk of financial institutions increases (decreases) in a similar fashion over varying time periods. As part of the analysis we will look at a number of aspects. Firstly we will examine the relative financial institution capital levels of the two countries. Although bank capital covers a number of different risks, credit risk is an extremely important component of capital adequacy, and higher credit risk should be reflected in higher capital levels. Secondly we will examine relative levels of credit risk for these countries using nonperforming loans and fluctuating asset values, applying various metrics, including Value at Risk (VaR), Conditional Value at Risk $(\mathrm{CVaR})$ and quantile regression.
\end{abstract}

Following the Global Financial Crisis, there has been much criticism leveled at risk management techniques which measure volatility below a specified threshold. One such technique is Value at Risk (VaR). A major criticism is VaR says nothing of the risk beyond that threshold. Conditional Value at Risk (CVaR), on the other hand, measures extreme risk, those risks beyond VaR. Quantile regression divides a dataset into parts, allowing the extreme quantiles to be isolated and measured. Using these techniques, we compare the credit risk of two data sets (US and Australia) over an eleven year time period from 2004 to 2014. This period includes a range of economic circumstances, spanning pre-GFC, GFC and post-GFC. For credit risk we use non-performing loans, as well as a Merton type model which measures volatility in the market asset values of borrowers. We derive a beta which measures credit risk relative to a benchmark. We then compare relative beta changes over time for the two countries.

There are a number of important elements and findings highlighted by the paper. Firstly, on an absolute capital basis (equity to assets), as measured by the World Bank, Australian financial institutions have low capital in comparison to their global peers, with a capital ratio that is about half that of US banks. However, the ratio improves substantially on a risk-weighted basis (per the Basel approach), to one that is much closer to US Banks. Australian Banks have a very high home loan component, with home loans attracting a low risk weighting for capital adequacy requirements. Thus there is a much bigger differential between absolute capital ratios and risk weighted capital ratios for Australia than for the US. Secondly the credit risk of Australian financial institutions as measured by the World Bank for non-performing loans is very low in relation to global banks, and is about half that of the US. Thirdly, when we apply measurements such as VaR, $\mathrm{CVaR}$ and quantlile regression to non-performing assets and conduct a Beta analysis to measure fluctuations in credit risk, we find that risk for Australian financial institutions moves in line with that of the US. During the GFC, the risk for Australia increased by very similar levels to that of the US, although off a much smaller base. The findings can be important to banks and regulators in understanding credit risk in these countries as well as choosing modelling techniques which are able to measure extreme risk and respond to changing economic circumstances, and thus provide early warning signs of changes in credit risk.

Keywords: Quantile regression, Conditional Value at Risk, credit risk 
Allen et al., Quantile regression, VaR and CVAR.

\section{INTRODUCTION}

\subsection{Background to the Study}

The spotlight on the risk management of banks around the globe intensified dramatically following the Global Financial Crisis (GFC). Basel III stepped up capital adequacy regulations, including the requirement (over a stepped period) for overall increased capital, the introduction of equity ratios and a greater focus on Common Equity Tier 1 Capital (CET). Countries undertook in depth investigations of their banking systems such as Dodd-Frank in the United States and the Murray Inquiry in Australia. Some of the findings and recommendations in the Murray Inquiry related specifically to credit risk, in that the report recommended that additional capital be held by banks to protect against loan risk, and that floors be set on the risk weightings that apply to home loans.

Capital adequacy relates to a range of risks, such as credit risk, market risk, liquidity risk and operational risk. There is no doubt, however, that a substantial portion of the focus is aimed at credit risk. That credit risk is by far the biggest risk in banking was recognized well before the events of the GFC (Bank for International Settlements, 2000; Reserve Bank of Australia, 1997). Since the GFC, credit risk has gained further attention, with credit risk and lax lending standards seen as major contributor to the crisis (Crotty, 2009; Dell'Ariccia, Igan, \& Laeven, 2012). The Australian Prudential Regulation Authority (APRA, 2015a) has a strong focus on credit risk and capital, with three prudential standards aimed specifically at credit risk, including APS 112 Capital Adequacy Standardised Approach to Credit Risk, APS 113 Internal Ratings Based Approach to Credit Risk and APS 220 Credit Risk. There are also additional APRA prudential standards which apply to credit related aspects, such as securitization, covered bonds, large exposures and credit cards.

The debate on credit risk and capital in Australia has not only heated up with the advent of the GFC and the Murray report, but escalating house prices in 2015 fuelled by all-time low interest rates and strong investor demand, particularly in Sydney and Melbourne, have generated strong debate on potential risks to the economy, if not a housing bubble, with regulatory measures being introduced to improve capital and increase controls on the provision of investment property finance.

Given the importance of credit risk and the strong current focus on this topic in Australia, this study examines recent credit risk data (to end 2014) using a variety of metrics as outlined in Section 1.2. The aim is to provide an understanding, not only of the extent of credit risk, but also how credit risk changes (or not) in line with external events, using the US as a benchmark, and also providing some global comparisons.

\subsection{Data and Methodology}

Data is obtained from two main sources. Firstly, capital and NPL figures are obtained from World Bank (2015). Secondly, equity figures for calculating market asset values are obtained from Datastream (from which we also derive liability values typical of Corporates in each of our two markets). The data spans 11 years from 2004 - 2014. Our analysis sections include Bank Capital (Section 2), non-performing loans (Section 3), VaR and CVaR (Section 4) and quantile regression (Section 5). We will briefly summarize our approach here, with more explanation on methodology in each individual section.

Throughout the analysis we use the concept of Beta $(\beta)$, which we define as risk relative to a benchmark. This allows us to measure differences between regions or periods on a common basis. In the Capital section, we use $\beta$ to measure Australian and US bank capital relative to global banks. We then do the same for NPL's, and also use $\beta$ to measure NPL for each individual year relative to the 11 year average NPL. In the VaR and $\mathrm{CVaR}$ section, these metrics are further explained, but in essence VaR measures risk at a particular level of confidence (we use 95\%), and CVaR measures the risk beyond VaR. We apply these metrics to measure extreme NPLs, as well as to measure extreme fluctuations in market values of assets. These market asset values are a core component of the Merton (1974) Distance to Default model, whereby asset volatility increases the chance of default as it lessens the gap between assets and liabilities. The model deems a firm to default when asset values fall below liabilities (i.e. capital erosion). We use the S\&P500 index as a representative illustration of the US market when measuring asset fluctuations and the All Ords index as representative of Australia. In both cases these indices represent 500 entities. We then use $\beta$ to compare differences in NPLs and asset values for the two countries as measured by VaR and CVaR. We also use $\beta$ to measure trends in asset values, i.e. $\mathrm{VaR}$ and $\mathrm{CVaR}$ for each individual year relative to the 11 year average.

Quantile regression (QR) divides a dataset into parts (quantiles). More about this metric is provided in the quantile regression section. We use QR to regress US NPLS and asset values against Australian values at different quantiles and compare differences between the countries at these quantiles. 
While prior studies have been undertaken on credit risk using various metrics, including the application of VaR, CVaR and quantile regression to market values, (D. Allen, Powell, \& Singh, 2014; D. E. Allen \& Powell, 2010; Powell \& Allen, 2009) this study builds on prior studies by applying these metrics to NPLs as well, and addresses the current focus on credit risk and capital by providing a comprehensive up to date picture of Australian credit risk relative to the US, using a wide variety of data and metrics in a single study.

\section{BANK CAPITAL}

In Table 1 Bank capital to total assets is presented, as measured by the World Bank (2015). The ranking, percentile and $\beta$ figures are our own metrics. The capital component of the ratio includes all capital and reserves (including Tiers 1, 2, 3 of capital as defined by Basel III), and assets include all financial and nonfinancial assets. In essence this is an equity ratio of shareholder equity to total assets.

Table 1. Bank Capital to Assets: Current and GFC.

\begin{tabular}{lcccc} 
& Bank Capital to Assets & & & \\
a. Current (2014) & Ratio \% & Rank (out of 131) & Percentile & $\beta$ \\
\hline Australia & 5.9 & 121 & $92.4 \%$ & 0.9 \\
US & 11.7 & 35 & $26.7 \%$ & 0.9 \\
\hline Global average & 10.2 & &
\end{tabular}

b. GFC (2009)

\begin{tabular}{lcccc}
\hline Australia & 6.3 & 113 & $81.9 \%$ & 1.6 \\
US & 12.4 & 32 & $23.2 \%$ & 0.8 \\
\hline Global average & 9.8 & &
\end{tabular}

Australia ranks very low in terms of the capital ratio by world standards and in comparison to the U.S. ranking. Australia's rank is 121 out of 151 regions, which places it at the $92.4 \%$ percentile (a slightly better $81.9 \%$ was seen during the GFC). The $\beta$ for Australia is calculated as Australia's ratio relative to the Global average (similarly for the US $\beta$ ), with a higher $\beta$ reflecting a lower capital, i.e. Australia's capital is $1.7 \mathrm{x}$ lower than the global average. Why then are Australian Banks generally considered to be well capitalized if their capital ratio is so low? This is because this ratio based on absolute asset values, whereas Basel capital is based on risk weighted asset figures. In particular, Australian Banks have a very high home loan component, with home loans on average having a much lower risk weighting than commercial assets. Based on risk weighted assets, Australian ADI's have a capital adequacy ratio of $12.5 \%$ according to APRA (2015b), compared to their total equity ratio of $5.9 \%$. The U.S. on the other hand has a risk weighted capital adequacy ratio of $14.9 \%$, compared to their equity ratio of $11.7 \%$ (Bankregdata, 2015). This shows how significantly the asset weightings of Australian banks have been discounted compared to the United States.

\section{NON-PERFORMING LOANS}

Table 2 shows non-performing loans (NPL) to total gross loans as reported by the World Bank (2015) for 131 countries. Figures are at year end December for each year. The $\beta$ in the last column is measured as the NPL figures for Australia and the U.S. relative to the global average. It is clear that, based on NPL, Australia is at the very low risk percentile of countries from a risk perspective (top 8.3\% at present, and top $12.9 \%$ during the GFC). The U.S. is currently in the top $19.7 \%$, but this was up to the $56.1 \%$ mark during the GFC.

Table 2. Non-Performing Loans: Current and GFC

\begin{tabular}{|c|c|c|c|c|}
\hline a. Current (2014) & $\begin{array}{c}\text { NPL to Total Gross } \\
\text { Loans }\end{array}$ & Rank (out of 131) & Percentile & $\beta$ \\
\hline Australia & 1.1 & 11 & $8.3 \%$ & 0.2 \\
\hline US & 2.0 & 26 & $19.7 \%$ & 0.3 \\
\hline
\end{tabular}

Global average

\begin{tabular}{lllll} 
& NPL to Total Gross & & \\
b. GFC (2009) & Loans \% & Rank (out of 131) & Percentile & $\beta$ \\
\hline Australia & 2.0 & 18 & $12.9 \%$ & 0.3 \\
US & 5.0 & 78 & $56.1 \%$ & 0.8 \\
\hline
\end{tabular}

Global average 
In table 3, NPL is shown from 2004 to 2014 (11 years), again based on World Bank figures. We calculate $\beta$ as the annual figure for that particular year, relative to the 11 year average for that country.

Table 3. Non-Performing Loans: Trend

\begin{tabular}{|c|c|c|c|c|c|c|c|}
\hline & \multicolumn{2}{|c|}{ Australia } & \multicolumn{2}{|c|}{ US } & \multicolumn{2}{|c|}{ Global } & \multirow{2}{*}{$\begin{array}{c}\text { Australia NPL / } \\
\text { US NPL }\end{array}$} \\
\hline & NPL \% & B & NPL \% & $\beta$ & NPL \% & B & \\
\hline 2004 & 0.2 & 0.2 & 0.8 & 0.3 & 7.2 & 1.2 & 0.3 \\
\hline 2005 & 0.6 & 0.5 & 0.7 & 0.3 & 6.2 & 1.0 & 0.8 \\
\hline 2006 & 0.6 & 0.5 & 0.8 & 0.3 & 4.9 & 0.8 & 0.7 \\
\hline 2007 & 0.6 & 0.5 & 1.4 & 0.6 & 4.2 & 0.7 & 0.4 \\
\hline 2008 & 1.3 & 1.0 & 3.0 & 1.2 & 4.0 & 0.7 & 0.4 \\
\hline 2009 & 2.0 & 1.6 & 5.0 & 2.0 & 6.2 & 1.0 & 0.4 \\
\hline 2010 & 2.1 & 1.7 & 4.4 & 1.8 & 7.0 & 1.2 & 0.5 \\
\hline 2011 & 2.0 & 1.6 & 3.8 & 1.5 & 6.4 & 1.1 & 0.5 \\
\hline 2012 & 1.8 & 1.5 & 3.3 & 1.3 & 6.6 & 1.1 & 0.6 \\
\hline 2013 & 1.5 & 1.2 & 2.5 & 1.0 & 7.0 & 1.2 & 0.6 \\
\hline 2014 & 1.1 & 0.9 & 2.0 & 0.8 & 7.1 & 1.2 & 0.6 \\
\hline Average & 1.2 & 1.0 & 2.5 & 1.0 & 6.1 & 1.0 & 0.5 \\
\hline
\end{tabular}

On absolute figures Australia clearly has a lower risk than the US, with an average NPL of approximately half of the US. The betas, showing movement, however, are not dissimilar. In 2008 and 2009, Australia had slightly lower betas than the US, meaning that bad debts had not yet increased as much as the US, but by 2010 to 2011, Australian betas had reached similar levels to the US. Thus Australia was not immune to the events of the GFC, with NPL's fluctuating to a similar extent as the US, although off a lower base.

For both Australia and the US, beta increases in the years leading up to the GFC, peaks in the 2009-2010 period and then reduces substantially thereafter. Globally, there is a lower level of fluctuation, but in essence the global NPLs just stay high all the time. This is because the Global figure includes some high NPLs from developing countries, and is also due to ongoing debt problems in some European countries. In particular the Global NPLs do not reduce following the GFC. Notable regional NPL's (current) as reported by the World Bank include Canada 0.5\%, China 1.1\%, UK 2.7\%, Euro Area 8.3\%, Greece 34\%. The comparable figures for the GFC are Canada 1.3\%, China 1.6\%, UK 3.5\%, Euro area 4.8\%, and Greece $6.3 \%$.

\section{VAR AND CVAR}

$\mathrm{VaR}$ is widely considered a benchmark measure for market risk, gaining substantial traction when incorporated as a metric for bank market risk in the Basel Accords. It measures the maximum risk at a given level of confidence (we use 95\%) for a selected time period. Popular measures of VaR include parametric (assumes a normal distribution) and nonparametric (makes no assumption about the distribution). A popular nonparametric measure is the historical simulation method, which sorts observations from best to worst, then measures $\mathrm{VaR}$ as the $95^{\text {th }}$ percentile observation. Details of $\mathrm{VaR}$ can be found in several publications (for example, Gregoriou, 2009; Jorion, 2001). Given that credit risk rarely follows a normal distribution and is rather characterized by a few large losses, we opt for the nonparametric historical distribution approach.

$\mathrm{VaR}$ has limitations, most notably that it ignores the risk beyond $\mathrm{VaR}$. This has led to the increasing popularity of $\mathrm{CVaR}$, which measures the risk beyond $\mathrm{VaR}$. If $\mathrm{VaR}$ is measured at the $95 \%$ level, then $\mathrm{CVaR}$ is the average of those risks beyond $\mathrm{VaR}$ - the worst $5 \%$ observations. CVaR has been applied in various market and credit risk studies (for example, Andersson, Mausser, Rosen, \& Uryasev, 2000; Menoncin, 2009). In addition to applying VaR and CVaR to NPLs in this section, we also apply these metrics to fluctuations in market asset values, a key component of the Merton (1974) Distance to Default (DD) credit model. The key components of the model are debt, equity, and fluctuations in market asset values.

A summary of the Merton formula is shown in equation 1 , where $V=$ market value of the firm, $F=$ debt, $\mu$ is the drift in asset values, $\sigma_{V}$ is volatility of asset values and $T$ is the forecast time period (usually 1 year).

$$
D D=\frac{\ln (V / F)+\left(\mu-0.5 \sigma_{v}^{2}\right) T}{\sigma_{v} \sqrt{T}}
$$

The numerator is a representation of the distance between the asset and debt values, i.e. the capital of the firm. When asset values fall below debt values the firm is deemed to default. As the volatility of market asset values (denominator) increases, DD becomes smaller and the probability of default higher. 
There are a number of complexities to measuring the market asset values. Given that the workings of the Merton model are well known, we will not explain these in any detail here, suffice it to say that we follow the approach outlined in Bharath and Shumway (2008). It summary, it involves estimating asset values every day as a combination of liability and market equity values, and then implementing a convergence and iteration and process to arrive at asset values. Typically banks would apply this to individual stocks, but here use the S\&P500 and ASX All Ords indices, which both have 500 entities, and are considered the benchmark indices for their countries, thus representing a typical large corporate entity in the two markets and providing a good indicator of overall asset volatility. We will not include the full DD calculations, only $\sigma_{V}$, as we are mainly interested in relative movements (volatility) between the two countries, which in turn impacts on DD.

We commence this part of our study with VaR and CVaR for NPL's as shown in Table 4.a. VaR is the $95^{\text {th }}$ percentile NPL figure for each country and CVaR the average of NPL's beyond VaR. For VaR and CVaR $\beta$, We use the same 11 year period as in Table 3, but we use quarterly changes in figures to give us a larger data set, as obtained from and apply these betas to the same 11 year average benchmark figures as used in the Table 3. The VaR and CVaR Betas in table 3 are not too dissimilar between the two countries, with Australia having a slightly lower VaR $\beta$ than the US and an equivalent CVaR $\beta$. This means that Australia was by no means immune to the events of the GFC, with NPL's fluctuating to the same extent as the US, although off a lower base. VaR and CVaR have not been calculated for Global figures due to not having quarterly NPL's.

Table 4. VaR and CVaR: NPL's and Asset Values

\begin{tabular}{lccc} 
a. NPLs & Australia $\beta$ & US $\beta$ & Australia / US \\
\hline VaR & 1.76 & 1.50 & 0.48 \\
CVaR & 1.81 & 1.88 & 0.46 \\
\hline
\end{tabular}

\begin{tabular}{|l|cc|cc|c|}
\cline { 2 - 6 } \multicolumn{1}{l|}{ b. Asset Values } & \multicolumn{2}{c|}{ Australia } & US & Australia / US \\
\hline VaR & Value & $\beta$ & 0.190 & $B$ & 0.75 \\
CVaR & 0.142 & 1.60 & 0.318 & 2.50 & 0.68 \\
\hline
\end{tabular}

Table 4b shows that Australia has lower VaR and CVaR values than the US (75\% of US VaR and $68 \%$ of US $\mathrm{CVaR}$ ) but that betas are not substantially different from the US. This means that the extent of the change in $\mathrm{VaR}$ and $\mathrm{CVaR}$ is similar for the two countries in line with changes in economic circumstances.

The figures in Table 4 also tell us something about the normality of the NPL and asset value distributions. Based on standard normal distribution tables, Betas for VaR at the 95\% level would be 1.645. Australia's NPL $\beta$ 's exceed this level, while the US VaR is slightly below. For asset values, Australia's VaR is fairly normally distributed, while the US VaR is below the normal level.

We have already undertaken an annual $\beta$ trend analysis for NPL's in Table 3, so we will restrict our $\beta$ trend analysis in Table 5 to asset values. The table shows that the US and Australia experienced a similar pattern, increasing prior to the GFC, peaking in 2008 and then reducing thereafter. It is noted that $\beta$ for asset values peaks slightly earlier (2008) than the $\beta$ 's for NPLs shown in Table 3 (which peak in 2009/2010). This is because asset values, in line with equity values, respond almost immediately on a daily basis to information and economic circumstances whereas there is a lag before this becomes reflected in NPL's.

Table 5. VaR and CVaR Trend - Asset Value Returns.

\begin{tabular}{|l|ccc|ccc|}
\cline { 2 - 6 } \multicolumn{1}{c|}{} & Stdev & Australia $\beta$ & & \multicolumn{3}{c|}{ US $\beta$} \\
& VaR & CVaR & Stdev & VaR & CVaR \\
\hline 2014 & 0.7 & 0.7 & 0.7 & 0.7 & 0.7 & 0.7 \\
2013 & 0.7 & 0.8 & 0.8 & 0.7 & 0.6 & 0.6 \\
2011 & 0.6 & 0.7 & 0.8 & 0.6 & 0.7 & 0.7 \\
2010 & 1.2 & 1.3 & 1.3 & 1.2 & 1.3 & 1.3 \\
2009 & 0.8 & 0.9 & 0.9 & 0.8 & 0.8 & 1.0 \\
2008 & 1.1 & 1.2 & 1.1 & 1.1 & 1.2 & 1.3 \\
2007 & 2.0 & 2.3 & 2.3 & 2.0 & 2.8 & 2.7 \\
2006 & 1.2 & 1.4 & 1.5 & 1.2 & 1.1 & 1.1 \\
2005 & 0.7 & 0.9 & 0.8 & 0.7 & 0.5 & 0.5 \\
2004 & 1.0 & 0.5 & 0.5 & 1.0 & 0.6 & 0.5 \\
& 1.0 & 0.4 & 0.4 & 1.0 & 0.6 & 0.6 \\
\hline
\end{tabular}


Allen et al., Quantile regression, VaR and CVAR.

\section{QUANTILE REGRESSION}

Quantile regression is a technique which compares relationships between two datasets by dividing them into parts (quantiles), allowing the researcher to isolate and examine a particular quanile. The concept was introduced and expanded on by Koenker and Bassett (1978) and Koenker and Hallock (2001). Any two relationships can be examined, for example school quality versus student performance (Eide \& Showalter, 1998) or exchange rates and stock prices (Tsai, 2012).

Quantile reression minimizes the sum of symetrically weighted residuals, yielding a median where $50 \%$ of residuals fall on either side (for the $50 \%$ quantile), or $90 \%$ and $10 \%$ for the $90 \%$ quantile and so on, as per the following formula:

$$
\min _{\varepsilon \in R} \sum p_{r}\left(y_{1}-\varepsilon\right)
$$

Quantile regression could be applied in different ways to understand credit risk, such as comparing two different time periods of the same dataset at different quantiles (e.g. pre-GFC to GFC), or can be used could split a single dataset into different quantiles to measure risk at different percentiles, or can be used to compare two entirely different datasets at varying quantiles. Here we provide some examples of these approaches for the Australia and the US NPL's and asset value returns.

Figure 1 compares NPL's of the US (y axis) to those of Australia (x axis). We also have betas in this analysis (being the slope of the line), but in addition (as is the norm with regressions) we need to add the intercept, where $y=\beta x$. The bold line is the $50 \%$ quantile (the best fitting median line which divides the dataset into two). By reading off the line (and looking at the details in the table next to the figure), we see that at this quantile (50\% of cases), the US NPL will be 2.139 for an Australian NPL of 1 . In $95 \%$ of cases (top line), the US NPL will not exceed 2.834 for an NPL of 1 . The bottom line of the graph (5\% quantile) shows that not even at the best case 5\% level are US NPL's better than Australia's. Overall the figures clearly illustrate the higher credit risk shown by US NPL's as compared to Australia.

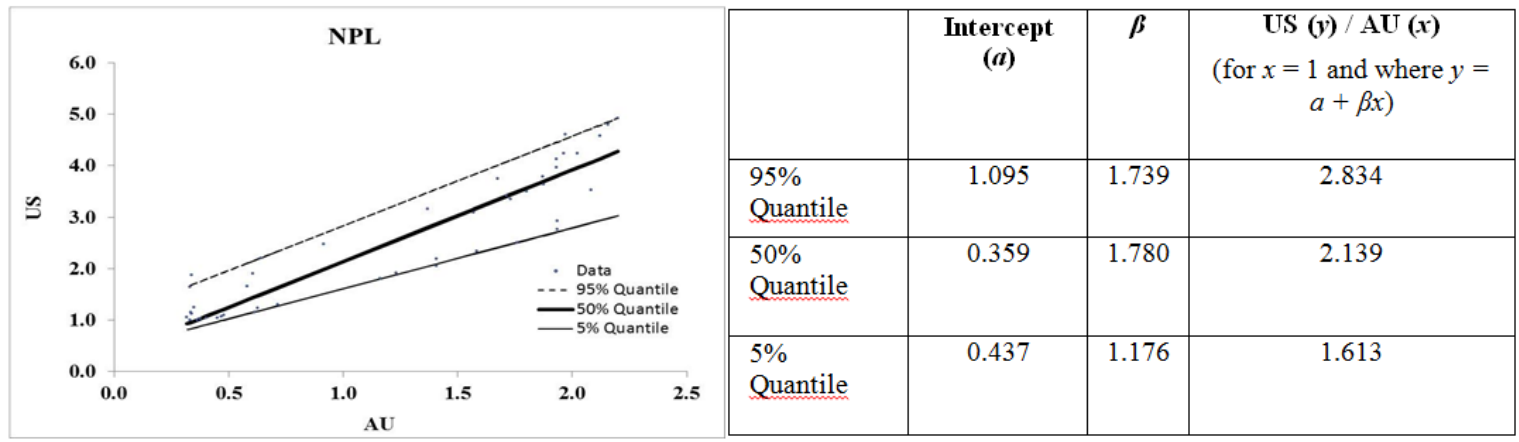

Figure 1. Quantile Regression of NPL's

When analysing market asset value returns in a similar manner, (we do not show a graph as the high number of daily returns make it very cluttered), we find that the U.S. has a 1.3x greater risk than Australia at the 95\% quantile for the whole 11 year period, and 1.4x for the 95\% quantile in the GFC period alone (2007 to 2009). Australia's 95\% quantile risk increases 1.5x from Pre-GFC (2004-2006) to GFC which is similar to the US. Given that the denominator of the DD equation measures volatility in asset values, an increase in the asset values will yield a similar increase in DD.

\section{CONCLUSIONS}

We have seen that using metrics which highlight tail risk such as quantile regression and CVaR can provide important information about credit risk, and changes in credit risk of one party relative to another, in our case Australia compared to the United States. The comprehensive analysis using a wide range of metrics has made some relationships very clear. Firstly, Australian financial institutions have a much lower level of absolute capital as measured by the World Bank than the US (and the global average), although this becomes much closer on a risk-weighted basis, due to the large home loan component of Australia's loan book, which permits a large discount on risk weights. Thus Australia has a much larger spread between absolute capital and risk weighted capital. Secondly, it is evident on all measures that Australia's credit risk is much lower than that of the US (and the global average), providing a case that a lower level of absolute capital may be warranted. Thirdly, it is evident that that Australia experiences only a slightly lower level of changes in credit 
Allen et al., Quantile regression, VaR and CVAR.

risk than the US: when circumstances have changed in the period of our analysis, such as the onset of the GFC, Australia's credit risk has increased by a similar percentage to the US, although at a lower level. This information is important to banks and regulators. While Australia may have lower credit risk, it is not immune to changing economic circumstances and has less capital to protect it. In a period of home loan stability, this may be justified, as stable home loans provide much lower risk weightings. But if there was an increase in risk in the large Australian home loan market, such as a major cooling off of house prices, Australia's low absolute capital makes it vulnerable. Thus the current focus on residential property lending in Australia by regulators, including increased capital and greater controls over investment property lending, could be a prudent approach.

\section{REFERENCES}

Allen, D., Powell, R., \& Singh, A. K. (2014). Take it to the limit: Innovative CVaR applications to extreme credit risk measurement. European Journal of Operational Research.

Allen, D. E., \& Powell, R. J. (2010). The fluctuating default Risk of Australian banks. Australian Journal of Management, 37(2), 297-325.

Andersson, F., Mausser, H., Rosen, D., \& Uryasev, S. (2000). Credit risk optimization with conditional Value-at Risk criterion. Mathematical Programming, 89(2), 273-291.

Australian Prudential Regulation Authority. (2015a). Authorised Deposit-taking Institutions (ADIs) Prudential Framework. Retrieved 28 July 2015. Available at www.apra.gov.au

Australian Prudential Regulation Authority. (2015b). Quarterly Authorised Deposit-taking Institution Performance.

Bank for International Settlements. (2000). Principles for the management of credit risk: Basel Committee for Banking Supervision Report.

Bankregdata. (2015). Retrieved 27 July, 2015. Available at http://bankregdata.com/allHMmet.asp?met=TOT

Bharath, S., \& Shumway, T. (2008). Forecasting default with the Merton distance-to-default model. The Review of Financial Studies, 21(3), 1339-1369.

Crotty, J. (2009). Structural causes of the global financial crisis: A critical assessment of the 'new financial architecture'. Cambrige Journal of Economics, 33(4), 663-580.

Dell'Ariccia, G., Igan, D., \& Laeven, L. (2012). Credit booms and lending standards: evidence from the subprime mortgage market. Journal of Money, Credit \& Banking, 44(2-3), 367-384.

Eide, E., \& Showalter, M. H. (1998). The effect of school quality on student performance: a quantile regression approach. Economics Letters, Elsevier, 58(3), 345 - 350.

Gregoriou, G. N. (2009). The VaR Modeling Handbook. New York: McGraw Hill.

Jorion, P. (2001). Value at Risk: The New Benchmark for Managing Financial Risk (2 ed.). New York: McGraw-Hill.

Koenker, R., \& Bassett, G., Jr. (1978). Regression quantiles. Econometrica, 46(1), 33-50.

Koenker, R., \& Hallock, K. (2001). Quantile regression. Journal of Economic Perspectives, 15(4), 143 - 156.

Menoncin, F. (2009). Using CVaR to optimize and hedge portfolios. In G. N. Gregoriou (Ed.), The VaR Modeling Handbook. New York: McGraw Hill.

Merton, R. (1974). On the pricing of corporate debt: The risk structure of interest rates. Journal of Finance, 29, 449-470.

Powell, R., \& Allen, D. (2009). CVaR and credit risk management. In Anderssen, R.S., R.D. Braddock and L.T.H. Newham (eds) 18th World IMACS Congress and MODSIM09 International Congress on Modelling and Simulation. Modelling and Simulation Society of Australia and New Zealand and International Association for Mathematics and Computers in Simulation, July 2009, pp. 1508-1514.

Reserve Bank of Australia. (1997). Credit risk in banking. Reserve Bank of Australia Bulletin, 1197(3).

Tsai, I. (2012). The relationship between stock price index and exchange rate in Asian markets: A quantile regression approach. Journal of International Financial Markets, Institutions and Money, 22, Issue 3, July 2012, Pages 609-621(3), 609-621.

World Bank. (2015). Data. Retrieved 28 July, 2015. Available at http://data.worldbank.org/ 